\title{
DYNAMICS OF THE MAGNETIZATION OF A SINGLE-DOMAIN DEFORMED SOFT MAGNETIC FERROMAGNET
}

\section{Igor P. Yermolenko}

Student, Department of Theoretical Physics and Wave Processes, Volgograd State University yermolenkoigor@volsu.ru

Prosp. Universitetsky, 100, 400062 Volgograd, Russian Federation

\section{Nikolay G. Lebedev}

Doctor of Physical and Mathematical Sciences, Professor, Department of Theoretical Physics and Wave Processes, Volgograd State University nikolay.lebedev@volsu.ru Prosp. Universitetsky, 100, 400062 Volgograd, Russian Federation

\begin{abstract}
On the basis of the quantum model taking into account the Zeeman energy and the energy of the crystal field, dynamic equations of Landau Lifshitz - Hilbert type for the magnetization of the deformed single-domain $\alpha$-Fe crystal are obtained. The domain deformation is taken into account in the framework of a linear approximation. The equations of motion are solved numerically using the Adams - Multon, Rosenbrock, and RADAU5 methods. It is shown that for some values of the model parameters, the dependence of the magnetization on the strength of an external magnetic field has the characteristic form of a hysteresis loop. Qualitative agreement of the model dependence of the coercive force on the applied longitudinal pressure with similar experimental data for various steel grades Durehete 1055, AS1548-7-46OR, X70, 11HN3D is obtained.
\end{abstract}

Key words: model Hamiltonian, Zeeman energy, crystal field, magnetic anisotropy, magnetization, hysteresis.

\section{Introduction}

The micro-magnetic theoretical calculation of the distribution of magnetization in samples of ferromagnets of various nature and structure is one of the most important areas of world research on the properties of magnetic materials. A rigorous analytical description 
of the magnetization dynamics encounters numerous difficulties that are overcome by constructing mathematical models, such as Stoner-Wolfart, Giles-Atherton, Hauser, and others, based on solving nonlinear differential equations [13].

In addition to the fundamental importance, the construction of phenomenological models of magnetic materials has practical significance. In particular, an experimental and theoretical study of the magnetic response of a sample to its deformation (the Villari effect) is carried out for more than a century [5;8]. In [15], the author experimentally studied the dependence of the parameters of the magnetic hysteresis loop of steel on the magnitude of the relative deformation. In particular, the nonlinear dependence of the coercive force of the studied samples on the magnitude of the uniaxial strain is shown. Similar dependences are obtained in $[3 ; 4]$.

One of the first approaches to constructing a model of magnetomechanical interactions in ferromagnetic dielectrics is the paper [16]. In the framework of the approximation of a continuous medium and a spin continuum, the author is obtained a system of coupled differential equations and boundary conditions for describing the macroscopic behaviour of non-conducting saturated ferromagnets subject to strong deformations.

In $[6 ; 7]$, authors are developed a quantum model of a soft magnetic single-domain ferromagnet without mechanical stresses in weak magnetic fields using the example of the $\alpha$-iron crystal. Using the constructed model Hamiltonian in the framework of the Heisenberg representation, nonlinear equations of a motion (Landau-Livshits-Hilbert type equations) are obtained for a magnetization and an orbital domain momentum taking into account a magnetic friction introduced phenomenologically through a magnetic field created by conduction currents in crystals. Two series of numerical experiments are carried out: for single domain and a set of domains with uniform distributed easy magnetization axes, in which the dependence of the projection of magnetization on the external magnetic field is calculated. In both cases, the calculated dependence has a characteristic hysteresis loop. In the multi-domain case, characteristic Barkhausen jumps are observed on the loop, arising as a result of a magnetization jump from one region of stable equilibrium to another for each domain.

In [14], the micro-magnetic approach developed in [6;7] is applied for modelling a deformed magnetic soft ferromagnet. Nonlinear dynamic Landau - Livshits - Gilbert type equations are transformed to a Bloch - Bloembergen type equation. On the basis of the numerical solution of the equations, the qualitative and quantitative agreement of the nonlinear dependence of the coercive force of a ferromagnet on the magnitude of uniaxial deformation with experimental data given in $[3 ; 4 ; 15]$ is obtained.

In this work, the microscopic model from [7] is applied to study the dynamics of a single-domain deformed magnetically soft ferromagnet using the example of the $\alpha$-iron crystal. The numerical solution of the initial dynamic Landau - Livshits - Hubert type equations is carried out. The dependence of the parameters of the hysteresis loop on the magnitude of the uniaxial strain is studied.

\section{Model of single-domain ferromagnet deformed}

The model of ferromagnet deformed is constructed in accordance with [7]. The effective Hamiltonian of single domain of a magnetically soft ferromagnetic with volume $v$ is constructed as the sum of the crystalline field Hamiltonians $\hat{H}_{K}$ and Zeeman $\hat{H}_{Z}$ interac- 
tions:

$$
\hat{H}=\hat{H}_{Z}+\hat{H}_{K},
$$

Zeeman energy operator of the domain in the external magnetic field strength $\mathbf{H}$ have known term:

$$
\hat{H}_{Z}=-g \mu_{B} \mu_{0} \hat{\mathbf{J}} \hat{\mathbf{H}}_{e}
$$

Where $\mu_{B}=e \hbar / 2 m$ is Bohr magneton, $\mu_{0}$ is the permeability of a vacuum, $g$ is the Lande factor, $\mathbf{H}$ is the external magnetic field, $\hat{\mathbf{J}}$ is the total mechanical momentum operator of a domain.

After applying the method of the equivalent operators $[1 ; 11]$ an effective crystal field Hamiltonian is obtained:

$$
\begin{gathered}
H_{K}=-W\left(\frac{\hat{J}_{x}^{4}+\hat{J}_{y}^{4}+\hat{J}_{z}^{4}}{N^{3}}\right), \\
\Phi_{0}=\frac{e^{2}}{4 \pi \varepsilon_{0} a} \approx 5.04 \mathrm{eV}, \quad W=\Phi_{0} \frac{5 \cdot 7 !}{8}\left(\frac{a_{B}}{2 Z a}\right)^{4} \approx 2.5 \mu \mathrm{eV},
\end{gathered}
$$

where $a=2.86 A$ is the parameter of bcc $\alpha$-Fe crystal lattice [2], $a_{B}=0.53 A$ is Bohr radius, $\mathrm{Z}$ is atomic number, $\varepsilon_{0}$ is the dielectric constant, $e$ is an elementary charge, $N=v / a^{3}$ is the number of elementary cells in the domain, $\hat{J}_{\alpha}$ is the $\alpha$-component $(\alpha=x, y, z)$ of the total mechanical momentum operator of a domain.

The deformed state of the crystal sample is characterized by the symmetric part of the distortion tensor - the strain tensor $u_{\alpha \beta}$ [9]. An arbitrary point $\mathbf{r}$ of the crystal is displaced to a new position $\mathbf{r}^{\prime}$, associated with the original by known relation:

$$
\begin{gathered}
\mathbf{r}^{\prime}=\mathbf{r}+\hat{u} \mathbf{r}, r_{\alpha}^{\prime}=r_{\alpha}+u_{\alpha \beta} r_{\beta}=r_{\alpha}+(\hat{u} \mathbf{r})_{\alpha}, \\
r_{\alpha}^{\prime 2}=r_{\alpha}^{2}+2 u_{\alpha \beta} r_{\alpha} r_{\beta}+u_{\alpha \beta} u_{\alpha \gamma} r_{\beta} r_{\gamma}, \\
r^{\prime}=\left(r_{\alpha}^{2}+2 u_{\alpha \beta} r_{\alpha} r_{\beta}+u_{\alpha \beta} u_{\alpha \gamma} r_{\beta} r_{\gamma}\right)^{1 / 2},
\end{gathered}
$$

where $\alpha, \beta, \gamma=x, y, z$. As a result of a deformation the crystal field of a ferromagnet, whose potential comprises power functions of electron coordinates, is changed:

$$
\begin{gathered}
r_{\alpha}^{\prime 4}=r_{\alpha}^{4}+4 r_{\alpha}^{3} u_{\alpha \beta} r_{\beta}+6 r_{\alpha}^{2}\left(u_{\alpha \beta} r_{\beta}\right)^{2}+4 r_{\alpha}\left(u_{\alpha \beta} r_{\beta}\right)^{3}+\left(u_{\alpha \beta} r_{\beta}\right)^{4}, \\
r^{\prime 4}=\left(r_{\alpha}^{2}+2 u_{\alpha \beta} r_{\alpha} r_{\beta}+u_{\alpha \beta} u_{\beta \gamma} r_{\alpha} r_{\gamma}\right)^{2}= \\
=r^{4}+4 r^{2} u_{\alpha \beta} r_{\alpha} r_{\beta}+2 r^{2} u_{\alpha \beta} u_{\beta \gamma} r_{\alpha} r_{\gamma}+4\left(u_{\alpha \beta} r_{\alpha} r_{\beta}\right)^{2}+\ldots
\end{gathered}
$$

Accounting linear terms of deformation leads to the following transformation:

$$
\begin{gathered}
r_{\alpha}^{\prime 4} \approx r_{\alpha}^{4}+4 r_{\alpha}^{3}(\hat{u} \mathbf{r})_{\alpha}, \\
r^{4}=\left(r_{\alpha}^{2}+2 u_{\alpha \beta} r_{\alpha} r_{\beta}+u_{\alpha \beta} u_{\beta \gamma} r_{\alpha} r_{\gamma}\right)^{2} \approx r^{4}+4 r^{2} \mathbf{r} \hat{u} \mathbf{r} .
\end{gathered}
$$

Accounting only linear term of deformation, the energy of the domain in the crystal field (3) of the deformed crystallite after transformation (6) becomes next: 


$$
W_{K}=\frac{140 \Phi_{0}}{9 a^{4}} \sum_{n=1}^{4 N}\left({x^{\prime}}_{n}^{4}+y_{n}^{\prime 4}+{z^{\prime}}_{n}^{4}-\frac{3}{5}{r^{\prime}}_{n}^{4}\right)=W_{K}^{(0)}+W_{K}^{(1)}+W_{K}^{(2)},
$$

where $W_{K}^{(0)}$ is the domain energy in the undeformed crystal expressed by the formula (3), $W_{K}^{(1)}$ and $W_{K}^{(2)}$ are components of the magneto-elastic energy domain:

$$
\begin{gathered}
W_{K}^{(1)}=\frac{560 \Phi_{0}}{9 a^{4}} \sum_{n=1}^{4 N}\left\{r_{\alpha}^{3} u_{\alpha \beta} r_{\beta}\right\}_{n}, \\
W_{K}^{(2)}=\frac{336 \Phi_{0}}{9 a^{4}} \sum_{n=1}^{4 N} r_{n}^{2}\left\{u_{\alpha \beta} r_{\alpha} r_{\beta}\right\}_{n} .
\end{gathered}
$$

After applying the method of equivalent operators [1;11] and the transition to the domain operators with the $L S$-binding approximation, formulas (7) and (8) are represented as operators:

$$
\begin{gathered}
\hat{H}_{K}^{(1)}=-\frac{2 W}{N^{3}}\left(\hat{\mathbf{J}}^{(3)} \hat{u} \hat{\mathbf{J}}+\hat{\mathbf{J}} \hat{u} \hat{\mathbf{J}}^{(3)}\right), \\
\hat{H}_{K}^{(2)}=\frac{1152 W}{5 N} \hat{\mathbf{J}} \hat{u} \hat{\mathbf{J}}
\end{gathered}
$$

where it is introduced the vector $\hat{\mathbf{J}}^{(3)}=\left\{\hat{J}_{x}^{3}, \hat{J}_{y}^{3}, \hat{J}_{z}^{3}\right\}$.

Formulas (9) and (10) represent operators of the magneto-elastic energy of a ferromagnet in the framework of approximations described above.

Averaging operators of the total angular momentum $\hat{\mathbf{J}}_{i}=\left\langle\hat{\mathbf{J}}_{i}\right\rangle$ over a domain, it can obtain the equation for the averages in the Heisenberg representation:

$$
\frac{d \mathbf{J}}{d t}=-\frac{i}{\hbar}\langle[\hat{\mathbf{J}}, \hat{H} \cdot]\rangle
$$

According to the commutation rules [10]:

$$
\left[\hat{J}_{\alpha}, \hat{J}_{\beta}\right]=i \varepsilon_{\alpha \beta \gamma} \hat{J}_{\gamma}
$$

where $\varepsilon_{\alpha \beta \gamma}$ is anti-symmetric unit tensor, one can calculate the commutators of the total angular momentum to switch components of the Hamiltonian (1) in the approximation of neglecting the dispersion of moment operators:

$$
\begin{gathered}
{[\hat{\mathbf{J}}, \hat{\mathbf{J}} \mathbf{H}]=\left[\mathbf{e}_{\alpha} \hat{J}_{\alpha}, \hat{J}_{\beta}\right] H_{\beta}=i \varepsilon_{\alpha \beta \gamma} \mathbf{e}_{\alpha} H_{\beta} \hat{J}_{\gamma}=i[\mathbf{H} \times \hat{\mathbf{J}}],} \\
{\left[\hat{\mathbf{J}},\left(\hat{J}_{\alpha}\right)^{4}\right]=4 i\left(\hat{J}_{\alpha}\right)^{3}\left[\mathbf{e}_{\alpha} \times \hat{\mathbf{J}}\right]} \\
{\left[\hat{\mathbf{J}}, u_{\beta \gamma} \hat{J}_{\beta} \hat{J}_{\gamma}\right]=\left[\mathbf{e}_{\alpha} \hat{J}_{\alpha}, u_{\beta \gamma} \hat{J}_{\beta} \hat{J}_{\gamma}\right]=2 i[\hat{\mathbf{u}} \hat{\mathbf{J}} \times \hat{\mathbf{J}}],} \\
{\left[\hat{\mathbf{J}}, u_{\beta \gamma}\left(\hat{J}_{\beta}^{3} \hat{J}_{\gamma}+\hat{J}_{\gamma} \hat{J}_{\beta}^{3}\right)\right]=2 i\left[\left(\hat{\mathbf{u}} \hat{\mathbf{J}}^{(3)}\right) \times \hat{\mathbf{J}}\right]+6 i\left[\left(\hat{J}_{\beta}^{2}\left(\mathbf{e}_{\beta} \hat{\mathbf{u}} \hat{\mathbf{J}}\right)\right) \mathbf{e}_{\beta} \times \hat{\mathbf{J}}\right] .}
\end{gathered}
$$


The end result that in the framework of Heisenberg representation the nonlinear equations of motion of a total mechanical momentum of a domain are obtained [7][10]:

$$
\begin{aligned}
& \frac{d \mathbf{J}}{d t}=-\mu_{0} \gamma\left[\mathbf{J} \times \mathbf{H}_{e}\right]-\frac{4 W}{N^{3} \hbar}\left[\hat{\mathbf{J}}^{(3)} \times \mathbf{J}\right]+\frac{460 W}{N \hbar}[(\hat{\mathbf{u}} \mathbf{J}) \times \mathbf{J}]- \\
& -\frac{4 W}{N^{3} \hbar}\left[\left(\hat{\mathbf{u}} \hat{\mathbf{J}}^{(3)}\right) \times \hat{\mathbf{J}}\right]+\frac{12 W}{N^{3} \hbar}\left[\left(\hat{J}_{\alpha}^{2}\left(\mathbf{e}_{\alpha} \hat{\mathbf{u}} \hat{\mathbf{J}}\right)\right) \mathbf{e}_{\alpha} \times \hat{\mathbf{J}}\right],
\end{aligned}
$$

where $\gamma=g \mu_{B} / \hbar$ is gyromagnetic ratio, $\mathbf{e}_{\alpha}$ are unit vectors of the easy magnetization axes, $\alpha=x, y, z$.

To transformation to the macroscopic model, the following quantities: $\mathbf{m}=-g \mu_{B}\langle\hat{\mathbf{J}}\rangle / \nu$ is the domain magnetization and $M_{s}=2 g \mu_{B} N / v$ is the saturation magnetization of the domain with the momentum value $J=2 N$ are introduced. Then the dynamic equations of macroscopic magnetization motion take the form:

$$
\frac{d \mathbf{m}}{d t}=\mu_{0} \gamma\left[\left(\mathbf{H}_{e}+\mathbf{H}_{K}\right) \times \mathbf{m}\right]
$$

where the crystal field strength of a domain:

$$
\mathbf{H}_{K}=\frac{M_{K}}{M_{S}^{3}}(\widehat{\mathbf{I}}+\widehat{\mathbf{u}})\left((\mathbf{m a})^{3} \mathbf{a}+(\mathbf{m b})^{3} \mathbf{b}+(\mathbf{m c})^{3} \mathbf{c}\right)-\frac{29 M_{K}}{M_{S}} \widehat{\mathbf{u m}} .
$$

In the expression (15) there are introduced the unit tensor notation $\mathbf{I}$, unit vectors of easy magnetization axes $\mathbf{a}, \mathbf{b}, \mathbf{c}$ coincident with the crystallographic axes [100], [010] and [001] of $\alpha$-Fe crystal, and the crystal field constants:

$$
M_{K}=\frac{32 W}{\mu_{0} \mu_{B} g} .
$$

Introducing the dimensionless time $\tau$ and the intensity of the alternating magnetic field $\mathbf{h}=\mathbf{h}_{\mathbf{0}} \sin (\omega t)$ according to the rule:

$$
\mathbf{H}_{e}=H_{0} \mathbf{h}, \quad \gamma \mu_{0} H_{0}=\Omega_{0}, \quad t=\frac{\tau}{\Omega_{0}}, \quad \mathbf{h}_{K}=\frac{\mathbf{H}_{K}}{\Omega_{0}}
$$

finally it is obtained the dimensionless dynamic equations of motion:

$$
\frac{d \mathbf{m}}{d \tau}=\left(\mathbf{h}_{e}+\mathbf{h}_{K}\right) \times \mathbf{m}
$$

To account for the magnetic friction the Landau damping is added as follow:

$$
\frac{d \mathbf{m}}{d \tau}+\alpha\left[\frac{d \mathbf{m}}{d \tau} \times \mathbf{m}\right]=\left(\mathbf{h}_{e}+\mathbf{h}_{K}\right) \times \mathbf{m},
$$

where $\alpha$ is damping coefficient taking into account the interaction of the local moment electrons to the conduction electrons.

In this case, the final equation of motion of the dimensionless magnetization of a domain becomes next:

$$
\frac{d \mathbf{m}}{d \tau}=\widehat{\mathbf{A}}(\mathbf{m})\left[\left(\mathbf{h}_{e}+\mathbf{h}_{K}\right) \times \mathbf{m}\right]
$$

where $\widehat{\mathbf{A}}(\mathbf{m})$ is the matrix defined components of the magnetization vector:

$$
\widehat{\mathbf{A}}(\mathbf{m})=\left(\begin{array}{ccc}
1 & \alpha m_{z} & -\alpha m_{y} \\
-\alpha m_{z} & 1 & \alpha m_{x} \\
\alpha m_{y} & -\alpha m_{x} & 1
\end{array}\right)^{-1}
$$




\section{The discussion of results}

The system of equations (20) is solved by Runge - Kutta type methods. And as complexity and hardness appear, the use of special techniques such as the Adams-Moulton, Rosenbroke and RADAU5 [12] is required. RADAU5 algorithm is based on the implicit fifth-order Runge - Kutta method, using quadrature Radau intended for solving systems of differential equations of different types (including "hard"). The results of the numerical solutions of equations (20) are shown in Figs.

Figure 1 shows the dependence of the projection of the domain magnetization of $\alpha$-Fe in the magnetic field direction on the value of the applied magnetic field strength. As it follows from the figure, the solution obtained has a characteristic form of the hysteresis loop. The oscillations in the vicinity of the coercive force can be explained by the appearance of numerical instabilities when switching the magnetization of the domain between two stationary solutions.

Figure 2 shows the dependence of the coercive force $H_{C}$ of $\alpha$-Fe single domain on the applied longitudinal pressure $p=\sigma_{x x}$, calculated over tensile deformation with the help of Young's modulus $E=2 \cdot 10^{11} \mathrm{~Pa}$. These results demonstrate directly the Villari effect, i.e. the dependence of the magnetization on the relative deformation. As seen from the figure, the calculated and locally smoothed by adaptive algorithm based on the analysis of the nearest neighbours of each data pair, the dependence is not linear in spite of the linear approximation with respect to a sample deformation. This is due to the nonlinearity of dynamic equations (20), which is caused by the influence of a cubic crystal field.

Comparison of the results (Figure 2) with the experimental data for various kinds of steels from $[3 ; 4 ; 15]$, is shown its qualitative agreement. Therefore, the proposed in [14], the deformed ferromagnet model can adequately describe the various manifestations of the Villari effect.

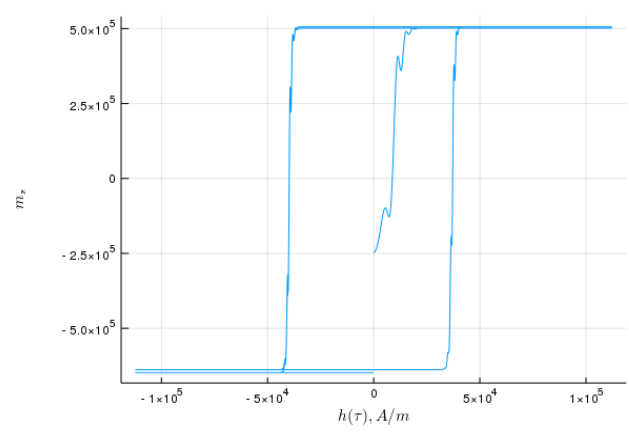

Fig. 1. The dependence of the $z$-component of the magnetization $m_{z}$ of $\alpha$-Fe crystal single domain on the value of the alternating magnetic field $h(\tau)$. Used parameter values: $M_{K}=3.1 \times 10^{2} M_{S}^{3}$,

$$
\omega=1, \alpha=0.04, u_{x x}=0.4, h_{0}=400
$$

\section{Conclusion}

Within the framework of the quantum approach the magnetization dynamics of singledomain deformed $\alpha$-Fe crystal with the Zeeman interaction and the crystal field is studied. Initial conditions and phenomenological parameters, under which the solution of the nonlin- 


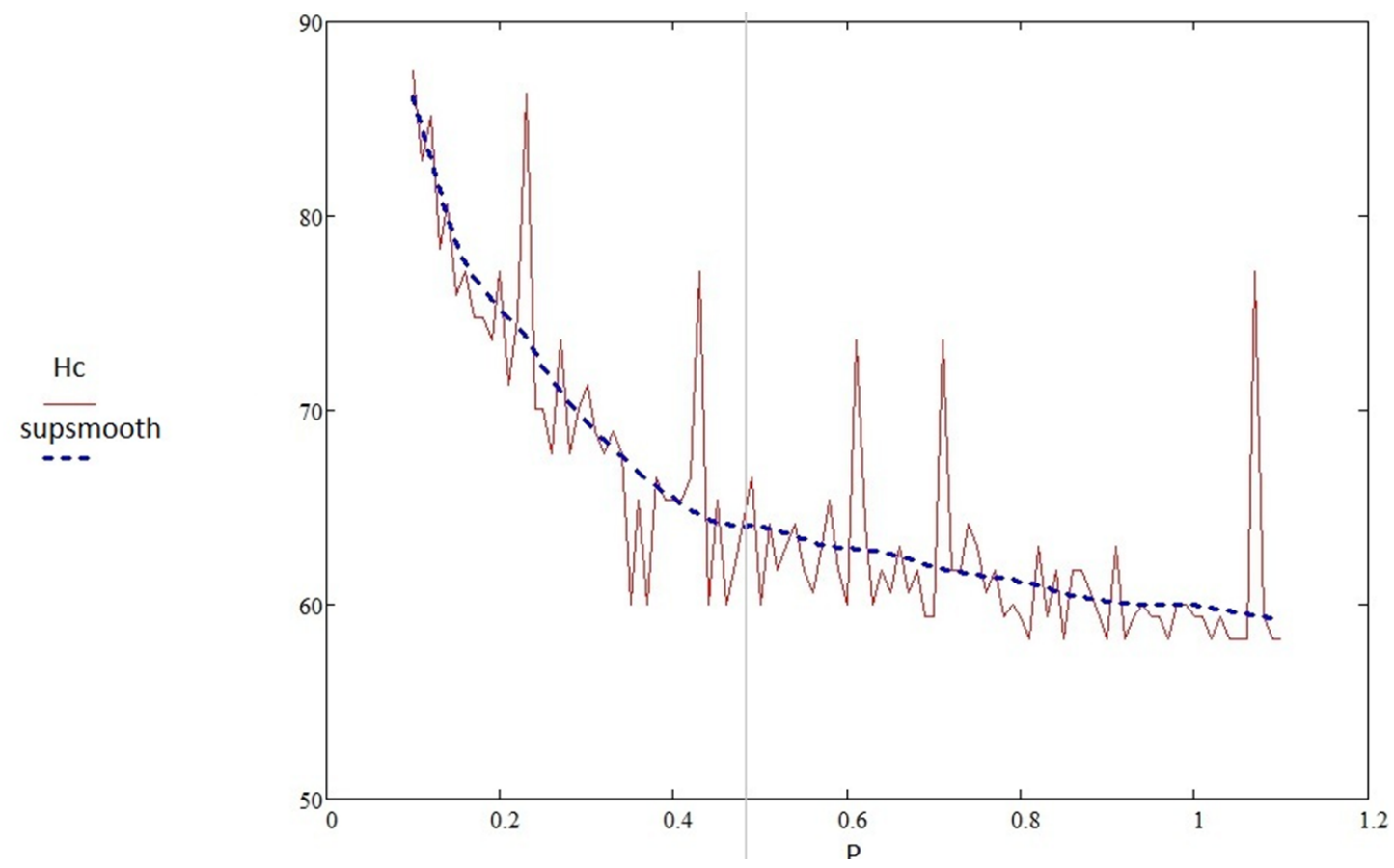

Fig. 2. The dependence of the coercive force $H_{C}$ of $\alpha$-Fe single domain on the applied longitudinal pressure $p=\sigma_{x x}$, calculated over tensile deformation with the help of Young's modulus $E=2 \cdot 10^{1} 1$

Pa. Used parameter values: $M_{K}=3.1 \times 10^{2} M_{S}^{3}, \omega=1, \alpha=0.04, u_{x x}=0.4, h_{0}=200$

ear equations of motion by the numerical Rosenbroke method has a characteristic dependence of the magnetization on applied magnetic field intensity in the form of the hysteresis loop, are selected. It is shown that within the linear approximation of the strain the dependence of the coercive force of the $\alpha$-Fe single domain on the applied longitudinal pressure qualitatively coincides with the experimental curves for samples of various types of steel (Durehete 1055, AS1548-7-46OR, X70, 11HN3D). Quantitative agreement between model results for these steel grades, but in the framework of the quadratic deformation approach, is shown in [14].

\section{REFERENCES}

1. Abragam A., Blini B. Elektronnyy paramagnitnyy rezonans perekhodnykh ionov [Electron Paramagnetic Resonance of Transition Ions]. Moscow, Mir Publ., 1973. $351 \mathrm{p}$.

2. Ashkroft N., Mermin N. Fizika tverdogo tela T. 1 [Solid State Physics Vol. 1]. Moscow, Mir Publ., 1979. 400 p.

3. Gorkunov E.S., Zadvorkin S.M., Putilova E.A., Savray E.A. Vliyanie struktury i napryazhennogo sostoyaniya na magnitnye svoystva metalla $\mathrm{v}$ razlichnykh zonakh svarnykh trub bolshogo diametra [The Influence of the Structure and Stress State on the Magnetic Properties of the Metal in Various Zones of Welded Pipes of Large Diameter]. Fizika metallov $i$ metallovedenie [The Physics of Metals and Metallography], 2014, vol. 115, no. 10, pp. 1011-1018.

4. Gorkunov E.S., Yakushenko E.I., Zadvorkin S.M., Mushnikov A.N. Vliyanie uprugikh deformatsiy na magnitnye kharakteristiki khromonikelevykh staley [The Effect of Elastic Deformations on the Magnetic Characteristics of Chromium-Nickel Steels]. Fizika metallov 
$i$ metallovedenie [The Physics of Metals and Metallography], 2015, vol. 116, no. 2, pp. 156-164. $1032 \mathrm{p}$

5. Vonsovskiy S.V. Magnetizm [Magnetism]. Moscow, Nauka Publ., 1971.

6. Ignatyev V.K., Lebedev N.G., Orlov A.A. Kvantovaya model gisterezisa v odnodomennom magnitomyagkom ferromagnetike [Quantum Model of a Hysteresis in a SingleDomain Magnetically Soft Ferromagnetic]. Fizika metallov $i$ metallovedenie [The Physics of Metals and Metallography], 2018, vol. 446, pp. 135-142.

7. Ignatyev V.K., Lebedev N.G., Nikitin A.V., Orlov A.A. Kvantovaya model gisterezisa v odnodomennom magnitomyagkom ferromagnetike [Quantum Model of a Hysteresis in a SingleDomain Magnetically Soft Ferromagnetic]. Fizika metallov i metallovedenie [The Physics of Metals and Metallography], 2018, vol. 120, pp. 227-238.

8. Krinchik G.S. Fizika magnitnykh yavleniy [Physics of Magnetic Phenomena]. Moscow, Izd-vo Mosc. un-ta, 1976. 367 p.

9. Landau L.D., Lifshits E.M. Teoreticheskaya fizika. T. III. Kvantovaya mekhanika [Theoretical Physics. Vol. III. Quantum Mechanics]. Moscow, FIZMATLIT Publ., 2004. $800 \mathrm{p}$.

10. Landau L.D., Lifshits E.M. Teoreticheskaya fizika. T. VII. Teoriya uprugosti [Theoretical Physics. Vol. VII. Theory of Elasticity]. Moscow, FIZMATLIT Publ., 2003. $264 \mathrm{p}$.

11. Lou V. Paramagnitnyy rezonans $v$ tverdykh telakh [Paramagnetic Resonance in Solids]. Moscow, Izd-vo inostrannoy literatury Publ., 1962. 242 p. $685 \mathrm{p}$

12. Khayrer V. Reshenie zhestkikh ODU [Solution of Stiff ODE]. Moscow, Mir Publ., 1999.

13. Cardelli E. Advances in Magnetic Hysteresis. Handbook of Magnetic Materials, 2015, vol. 24, pp. 323-409.

14. Ignayiev V.K., Lebedev N.G., Orlov A.A. Quantum Model of a Hysteresis in a SingleDomain Magnetically Soft Ferromagnetic. The Physics of Metals and Metallography, 2018, vol. 120 , pp. $477-486$.

15. Stevens K.J. Stress Dependence of Ferromagnetic Hysteresis Loops for Two Grades of Steel. NDT and E International, 2000, vol. 33, pp. 111-121.

16. Tiersten H.F. Coupled Magnetomechanical Equations for Magnetically Saturated Insulators. Journal of Mathematical Physics, 1964, vol. 5, pp. 1298-1318. DOI: 10.1063/1.1704239.

\section{ДИНАМИКА НАМАГНИЧЕННОСТИ ОДНОДОМЕННОГО ДЕФОРМИРОВАННОГО МАГНИТОМЯГКОГО ФЕРРОМАГНЕТИКА}

\section{Игорь Петрович Ермоленко}

Студент кафедры теоретической физики и волновых процессов, Волгоградский государственный университет yermolenkoigor@volsu.ru просп. Университетский, 100, 400062 г. Волгоград, Российская Федерация

\section{Николай Геннадиевич Лебедев}

Доктор физико-математических наук, профессор кафедры теоретической физики и волновых процессов, Волгоградский государственный университет nikolay.lebedev@volsu.ru просп. Университетский, 100, 400062 г. Волгоград, Российская Федерация

Аннотация. На основе квантовой модели, учитывающей зеемановскую энергию и энергию кристаллического поля, получены динамические урав- 
нения типа Ландау - Лифшица - Гильберта для намагниченности деформированного однодоменного кристалла $\alpha$-Fе. Учет деформации домена осуществлен в рамках линейного приближения. Полученные уравнения движения решались численно с помощью методов Адамса - Мултона, Розенброка и RADAU5. Показано, что при некоторых значениях модельных параметров зависимость намагниченности от напряженности внешнего магнитного поля имеет характерный вид петли гистерезиса. Получено качественное согласие модельной зависимости коэрцитивной силы от приложенного продольного давления с аналогичными экспериментальными данными для различных марок сталей Durehete 1055, AS1548-7-46OR, X70, 11ХН3Д.

Ключевые слова: модельный гамильтониан, зеемановская энергия, кристаллическое поле, магнитная анизотропия, намагниченность, гистерезис. 